\title{
Erratum to: Recommendations for the Health Economics Analysis to be Performed with a Drug to be Registered in Prevention or Treatment of Osteoporosis
}

\author{
W. Dere $\cdot$ B. Avouac $\cdot$ M. Boers $\cdot$ M. Buxton $\cdot$ C. Christiansen $\cdot$ \\ A. Dawson - C. Gennari - F. Guillemin - H. Lawaetz • \\ F. Ornskov $\cdot$ I. Roumagnac $\cdot$ J. Y. Reginster
}

Published online: 5 July 2013

(C) Springer Science+Business Media New York 2013

Erratum to: Calcif Tissue Int (1998) 63:93-97

DOI 10.1007/BF03322783

The name of one of the authors of this article was spelt incorrectly. Lawetz should be spelt Lawaetz. The corrected list of authors appears in this erratum.

The online version of the original article can be found under doi: $10.1007 / \mathrm{BF} 03322783$.

W. Dere

Diabetes Care \& Endocrinology, Lilly Research Laboratories,

Eli Lilly \& Company, Lilly Corporate Centre, Indianapolis,

IN 46285, USA

\section{B. Avouac}

Hospital Henri Mondor, 94010 Creteil, France

\section{Boers}

Department of Internal Medicine/Rheumatology,

University of Maastricht, Maastricht, The Netherlands

\section{Buxton}

Health Economics Research Group, Brunel, The University

of West London, Uxbirdge, Middlesex UB8 3PH, UK

C. Christiansen - H. Lawaetz

Center for Clinical \& Basic Research, Ballerup Byvej 222,

Ballerup 2750, Denmark

A. Dawson

Eli Lilly \& Company Ltd., Lilly Research Centre, Erl Wood

Manor, Windlesham, Surrey GU20 6PH, UK

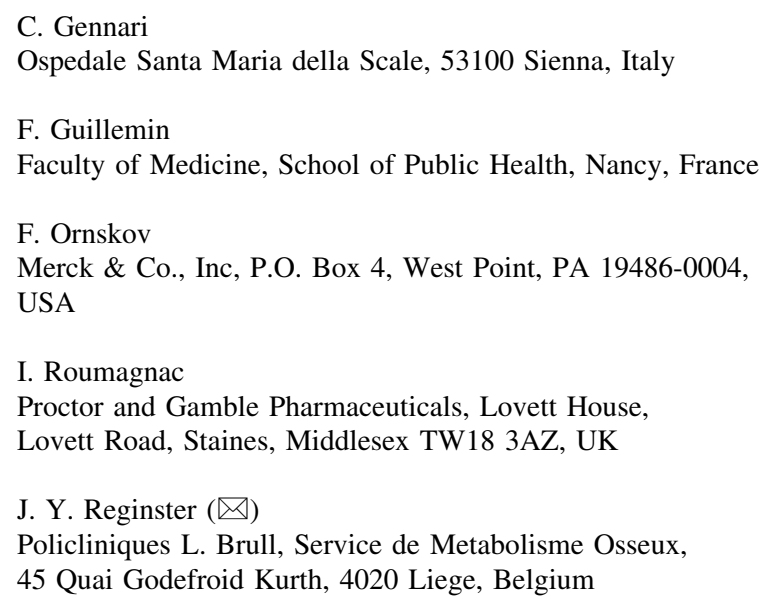

